\title{
Rio Comprido em seus aspectos históricos e geográficos: possibilidades
}

\author{
Rio Comprido in its historical and geographical aspects: possibilities
}

Andressa Lacerda ${ }^{1}$, Deborah Fontenelle ${ }^{2}$, Hilton Meliande de Oliveira ${ }^{3}$, Hilton Silva Junior ${ }^{4}$, Vinicius Moraes $^{5}$, Rejane Rodrigues ${ }^{6}$

\begin{abstract}
1 Professora Assistente. Departamento de Ciências Humanas e Filosofia do Instituto de Aplicação Fernando Rodrigues da Silveira da Universidade do Estado do Rio de Janeiro (DCHF, CAp-UERJ), Brasil. E-mail: andressa.lacerda@gmail.com

2 Professora Assistente. Departamento de Ciências Humanas e Filosofia do Instituto de Aplicação Fernando Rodrigues da Silveira da Universidade do Estado do Rio de Janeiro (DCHF, CAp-UERJ), Brasil. E-mail: fontenelle.deborah@gmail.com

3 Professor Adjunto. Departamento de Ciências Humanas e Filosofia do Instituto de Aplicação Fernando Rodrigues da Silveira da Universidade do Estado do Rio de Janeiro (DCHF, CAp-UERJ), Brasil. E-mail: meliandehilton@gmail.com

4 Professor Assistente. Departamento de Ciências Humanas e Filosofia do Instituto de Aplicação Fernando Rodrigues da Silveira da Universidade do Estado do Rio de Janeiro (DCHF, CAp-UERJ), Brasil. E-mail: jrhiltongeo@gmail.com

5 Professor Assistente. Departamento de Ciências Humanas e Filosofia do Instituto de Aplicação Fernando Rodrigues da Silveira da Universidade do Estado do Rio de Janeiro (DCHF, CAp-UERJ), Brasil. E-mail: vinnygnaise@gmail.com

6 Professora Adjunta. Departamento de Ciências Humanas e Filosofia do Instituto de Aplicação Fernando Rodrigues da Silveira da Universidade do Estado do Rio de Janeiro (DCHF, CAp-UERJ), Brasil. E-mail:rcarodrigues@gmail.com
\end{abstract}

Recebido em: 16/09/2016 | Aprovado em: 07/04/2017

DOI: 10.12957/interag.2017.25618

\section{Resumo}

O presente artigo que faz parte do projeto: Rio Comprido: lugar, memória e identidade, tem o intuito de recuperar e valorizar a memória identitária do bairro do Rio Comprido a partir de uma discussão histórica e geográfica e seus aportes teórico-conceituais, por uma perspectiva transversal de ensino, abordando temas que perpassam tais disciplinas, envolvendo as diferentes séries do Ensino Fundamental e Médio, com o objetivo de construir um ideal de conhecimento amplo, diversificado, crítico, respeitoso e libertário.

Palavras-chave: Evolução Urbana; Rio Comprido; Memória; Lugar.

\begin{abstract}
This article is part of the project Rio Comprido: place, memory and identity, and it aims at restoring and enhancing the identity memory of the Rio Comprido neighborhood, following a historical and geographical discussion and its theoretical and conceptual contributions, through a transversal perspective of education. Covering topics that run through these disciplines, involving the different grades of primary and secondary education, with the goal of building an ideal of knowledge that is broad, diverse, critical, respectful and libertarian.
\end{abstract}

Keywords: Urban Development; Rio Comprido; Memory; Place.

Área temática: Educação

Linha de extensão: Metodologias e estratégias ensino/aprendizagem. 
"A articulação da história como um lugar é a condição de uma análise da sociedade" 1

“A 'memória urbana' é hoje um elemento fundamental da constituição da identidade de um lugar"2

\section{O bairro do Rio Comprido: breve histórico}

Pensar nas possibilidades de estudo referentes a um lugar é refletir nas potencialidades de diversos campos de conhecimento. Sendo assim, estudar sobre um bairro é se debruçar em suas questões históricas, geográficas e na gama de possibilidades que tais compreensões remetem para os campos sociais, políticos, econômicos, dentre outros, e que exprime, ao fim e ao cabo, na interminável relação indivíduo, tempo e lugar, ou seja, na dimensão compreendida como e por sociedade.

Ao pensar sobre a história do Rio de Janeiro, sua construção e localidades, não se deve distanciar de suas questões e apontamentos geográficos, imprescindíveis para a sua ocupação e construção social. De acordo com Mauricio Abreu, "apertado entre o mar e a montanha, o Rio de Janeiro teve, nesses elementos naturais, os grandes balizadores de sua expansão.” ${ }^{3}$ A potencialidade hídrica, marcada a partir dos rios e suas possibilidades de navegação e abastecimento, também foram importantes marcos separando e nomeando diversas regiões que compunham e ainda fazem parte do atual Estado. ${ }^{4}$ Como apontou Elmo Amador ao destacar o estuário de São Diogo, região que dentre outras, englobava também o atual bairro do Rio Comprido:

O Estuário de São Diogo, também denominado Saco de São Diogo, era um extenso braço de mar, bastante largo em sua embocadura, que era balizada pela Gamboa à direita e pela ponta do Caju e Ilha dos Ferreiros à esquerda. Em direção ao interior o estuário se estreitava progressivamente sofrendo uma inflexão para a esquerda até atingir as imediações da atual Praça XI. No seu curso recebia a contribuição dos rios Iguassú (atual Rio Comprido), Maracanã, Trapicheiros, Joana e Catumbi, que descreviam meandros de maré no trecho de planície, serpenteando por extensos manguezais. ${ }^{5}$ 
O contexto histórico analisado por Amador se refere a um tempo em que o conceito destinado ao local não era de bairro e sim de freguesia. Tal denominação foi a primeira divisão para as regiões e seguiam uma jurisdição territorial de caráter religioso, de início, mas que depois ganharam definição administrativa, como apontou Noronha Santos. ${ }^{6}$ Segundo Fania Fridman,

As donatarias dividiam-se em comarcas abarcando os termos das vilas e cidades e estas se fracionavam em paróquias, "o que evidencia carência de sólida distinção conceitual entre poderes civil e eclesiástico, levando aquele a servir-se da freguesia, circunscrição deste, confirmando a regra, frequente, de a organização religiosa preceder à civil".?

Neste sentido, segundo a autora, "a freguesia, designação portuguesa de paróquia, é um território submetido à jurisdição espiritual de um cura que também exerce a administração civil”.7Desta forma, fica claro que os limites e denominações religiosas e político-administrativas se confundem, o que aparecerá mais para frente quando analisarmos topônimos ligados ao bairro.

Assim, o atual bairro do Rio Comprido de mesmo nome de um rio que cortava o bairro, localizado no eixo do sopé de encostas da vertente norte do Maciço da Tijuca, apresentou-se no século XVII como região produtora de cana- de- açúcar. Sua produção era destinada à baía e ao porto do Rio de Janeiro e se utilizava de embarcações que navegavam o rio em questão. Outra função do rio Comprido era o abastecimento de água para parte da cidade através do aqueduto do Catumbi. ${ }^{8}$

Neste momento, pode-se destacar que algumas moradias seguiam o leito do rio, iniciando-se o seu povoamento. Era através da navegação do rio Comprido que se chegava até a Cidade de São Sebastião do Rio de Janeiro.

Entretanto, foi no século XIX que a região do Rio Comprido apresenta significativo crescimento, tornando-se local para a instalação do Quartel General do Exército no período joanino, ou seja, momento em que graças às investidas napoleônicas na Europa e ao não cumprimento do Bloqueio Continental, a Corte Portuguesa vem para o Rio de Janeiro, fazendo-o de sede Governamental do Mundo Luso. 
No século em questão, o Rio Comprido também se apresentou como local de preferência para a moradia dos ingleses e pessoas abastadas, que desde o século XVIII adquiriram casas próprias, em sua maioria chácaras, ou viviam em pensões de compatriotas, como enfatizou Brasil Gerson. ${ }^{9}$

Das muitas chácaras existentes no bairro, a que recebeu maior destaque foi a Chácara do bispo frei Antônio do Desterro, construída ainda no Brasil Colonial no início do século XVIII e que, em 1891, se tornou o Seminário S. José, que antes estava estabelecido na rua da Ajuda, mas que se transferiu para o Rio Comprido. Neste interregno tempo até a chegada do Seminário, a antiga Chácara do Bispo, encravada na Sesmaria dos Jesuítas, serviu como casa de campo e chácara do segundo Bispo do Rio, Dom Frei Francisco de São Jerônimo, que ali instalou o Seminário Maior, o Colégio Episcopal de São Pedro de Alcântara. Atualmente a casa pertence à Fundação Roberto Marinho. ${ }^{8}$

Importante notar que a chácara em questão nomeou e renomeou partes do bairro. Um dos exemplos é a própria rua do Bispo, aberta em 1844 e que ainda hoje seu nome é uma alusão à esta antiga propriedade. Liga hoje as ruas Aristides Lobo e rua Estrela, assim denominada por situar o antigo Solar do Barão da Estrela. ${ }^{8}$

A rua Bela Vista, depois renomeada Barão de Itapagipe, homenagem ao Marechal Francisco Cabral Xavier da Silva, que possuía uma chácara no local, era a rua mais longa do bairro. Outros importantes indivíduos do império moravam na região como o Conde de Sucena, que dentre outros residiam em belos sobrados, palacetes e chácaras. Além destas moradias, destacam-se clubes que eram destinados ao lazer de seus moradores, transformando a região em um elegante bairro da cidade. ${ }^{9}$

Ainda, o século XIX pode ser compreendido como importante para o crescimento da região expandindo-a e incorporando novos sítios à área urbana. Até então, durante quase três séculos a cidade fica contida, apertada, entre os quatro morros: do Castelo, de São Bento, de Santo Antônio e da Conceição. Para além deles, como aponta Mauricio Abreu ${ }^{10}$, apenas alguns tentáculos corriam aos sertões do sul, do oeste e do norte. O sítio da cidade, composto por brejos e mangues, fora arduamente conquistado 
através de dessecamentos e da construção de pontes. $O$ desenvolvimento de técnicas, tanto na área de construção, como de aterramentos, como na área de transportes, permitiram que essa expansão ocorresse, mudando, significativamente, a cara da cidade.

Neste sentido, deve-se destacar a decisão da Câmara em 1850, que intensificou o aterro da região do Saco de São Diogo. Assim, em 1851, a planta de todo o mangue foi estruturada, o que permitiu o aterro e a construção de um canal de escoamento, o canal do Mangue, obra realizada pelo Barão de Mauá proporcionando a ampliação da ocupação da região, além de ser considerada como a maior obra de saneamento do Império, criando a Cidade Nova, que nos dias atuais também incluiu os bairros do Estácio, Catumbi, e parte do Rio Comprido. ${ }^{11}$

A ocupação foi tamanha que se constituiu a criação de uma nova freguesia denominada de Espírito Santo, que possuía a jurisdição sobre os atuais bairros do Catumbi, Estácio e Rio Comprido e parte de Santa Teresa, área desmembrada de terrenos pertencentes, anteriormente, às freguesias de Santo Antônio, Engenho Velho, Santana e São Cristóvão. Somada à ocupação da região, dever-se-ia buscar melhoramentos quanto ao saneamento da mesma; entretanto, transformaram o Canal do Mangue e seus afluentes em importantes condutores dos esgotos. Não foram realizados os devidos tratamentos, o que levou, por fim, ao aumento da intensidade de fluxos de água e de sedimentos, acarretando impactos indesejáveis como as enchentes, acontecimentos marcantes para a região. ${ }^{8}$

De acordo com Abreu,

Os vestígios desse tipo de ocupação são visíveis até hoje nas áreas que conseguiram sobreviver às cirurgias urbanas. São prédios estreitos e muito profundos, "onde a iluminação é feita através de clarabóias e áreas internas, sempre de frente da rua e colados uns aos outros”, em tudo revelando a preocupação de aproveitar intensamente o espaço próximo ao centro, numa época em que, devido à inexistência de transportes coletivos rápidos, a cidade praticamente andava a pé." ${ }^{11}$

Assim, pensando o ideal de desenvolvimento da região, os veículos sobre trilhos, os bondes, também chegaram ao Rio Comprido em fins do século XIX. Em 1870 foi criado o serviço da Rio de Janeiro Street Railway Company, que posteriormente seria a 
Companhia São Cristóvão, assistindo os bairros de São Cristóvão, Andaraí Pequeno (Tijuca), Saúde, Santo Cristo, Gamboa, Caju, Catumbi e também servia ao bairro do Rio Comprido. As transformações continuaram para a região do Mangue, como apontou Mauricio Abreu, criando novas companhias e linhas de bondes.

Nascia assim a Companhia Ferro-Carril de Vila Isabel, que entretanto só pôde inaugurar a sua primeira linha, ligando o Centro a Vila Isabel, em fins de 1873, devido a numerosos trabalhos de aterro e construção de ponte que se faziam necessários na área do Mangue, junto à foz do Rio Comprido. ${ }^{12}$

Nas ruas do bairro em questão habitavam, em fins do século XIX, muitos ilustres da política e sociedade brasileira. Como exemplo, pode-se citar a rua Santa Alexandrina, onde hoje se encontra o Instituto Fernando Rodrigues da Silveira, o CAp-UERJ. Essa foi a mesma rua onde morou Marechal Deodoro da Fonseca no momento da instauração da República. A rua Santa Alexandrina foi constituída em 1841, com o objetivo de acessar um aqueduto que se originava em Santa Teresa. ${ }^{8}$

Nas primeiras décadas do século $\mathrm{XX}$, momento político brasileiro em que se constituía a partir da estrutura republicana de governo, e que o Rio de Janeiro conheceria grandes transformações urbanas, não foi diferente para com o bairro do Rio Comprido. No ano de 1919, Paulo de Frontin, que era engenheiro de formação, foi nomeado Prefeito do Distrito Federal, e dentre suas realizações fez a abertura da Avenida Rio Comprido, atual Paulo de Frontin. Com a extensão de 1600 metros esta avenida tornouse a principal via do bairro. Sua importância aumentou com a inauguração do Túnel Rebouças no ano de 1967, tornando-se eixo fundamental para a interligação entre as regiões norte e sul da cidade do Rio de Janeiro. ${ }^{8}$

Tais modificações levaram ao fim do antigo bairro bucólico, transformando-o em bairro importante para o transitar/ trafegar do povo carioca, principalmente após a construção do elevado Engenheiro Freyssinet nos idos de 1970. Um fato marcante na construção do elevado, como apontou Brasil Gerson, foi o desabamento de uma parte do mesmo, em seu período de obras, deixando mortos e feridos. $\mathrm{O}$ acidente aconteceu no dia 20 de novembro de 1971, na esquina com a rua Haddock Lobo. ${ }^{13}$ 
A via em questão foi construída pela demanda e necessidade urbana crescente do Rio de Janeiro, ampliando o ideário do bairro, antes residencial, como local de passagem. Não se pode deixar de observar que tais transformações levaram a um processo de desvalorização do bairro à sua antiga estrutura aprazível e residencial. O barulho dos automóveis, a poluição e a própria limitação da luz natural, em decorrência do elevado, fizeram com que muitos antigos moradores procurassem outros lugares de moradia. ${ }^{8}$

Pode-se perceber também, no século XX, o aumento populacional nas encostas da vertente norte do Maciço da Tijuca por uma população de baixa renda, que somada ao descaso das autoridades e à necessidade de sobreviver ampliaram a expansão das favelas do Turano, do Fogueteiro, do Querosene e o Complexo Paula Ramos, comunidades do entorno. ${ }^{14}$

Deve-se deixar claro que este processo de favelização caminhou com o processo de urbanização carioca do início do século XX, que, dentre outros fatores pode-se destacar a necessidade das camadas mais pobres de morarem próximo ao centro e seus lugares de trabalho, além da falta de recursos para comprar moradias em regiões voltadas ao subúrbio e à linha férrea. ${ }^{15}$

Atualmente o bairro do Rio Comprido, assim como as áreas centrais do Rio de Janeiro, aos poucos vem sofrendo uma tentativa de revalorização de seu espaço urbano. Importantes instituições e atividades vêm sendo desenvolvidas no bairro como o Hospital do Corpo dos Bombeiros, o Sindicato das Empregadas Domésticas, o Campus Rebouças da Universidade Estácio de Sá, a Fundação Osório (integrante do sistema de Colégios Militares do Brasil), o Inmetro, o Canal Futura, a Fundação Cesgranrio, uma unidade da Unicarioca, sem esquecer do Instituto de Aplicação Fernando Rodrigues da Silveira, o CAp-UERJ. Várias lojas ligadas ao setor de malharias, além de outras atividades comerciais e de serviços, podem e devem ser vistos como indicativos da possibilidade de um processo de revitalização do Rio Comprido. ${ }^{14}$ 


\section{A proposta do projeto de extensão}

O bairro do Rio Comprido, onde se localiza o CAp-UERJ, apesar da aparente degradação de sua paisagem, conserva elementos que nos ajudam a compreender a história e a evolução urbana da cidade do Rio de Janeiro.

A percepção que a população da cidade tem do bairro é marcada pelo imaginário de lugar de passagem ao túnel André Rebouças, das ruas escuras e empoeiradas cobertas pelo elevado Engenheiro Freyssinet, da degradação de seu principal rio e da pobreza e violência relacionadas às favelas que o circundam. Ao citadino, que circula pelo bairro no fluxo veloz do cotidiano da cidade, passam despercebidas riquezas arquitetônicas, históricas, culturais, geográficas etc.

Neste sentido, a ideia deste trabalho é recuperar e valorizar a memória identitária do bairro do Rio Comprido pelo desenvolvimento de atividades voltadas à promoção e recuperação da riqueza arquitetônica e cultural do bairro, bem como da histórica e geográfica também. Além disso, pretende-se, ainda, que bairros adjacentes, como Santa Teresa, Catumbi e Estácio, se integrem à pesquisa como territórios que compõem a história do bairro e da cidade do Rio de Janeiro.

Assim, reunindo professores de Geografia e História do CAp-UERJ através de um trabalho interdisciplinar acerca do bairro do Rio Comprido, encontramos inúmeras possibilidades de abordagem de pesquisa. Neste artigo, tendo em vista que o projeto ainda se encontra em fase inicial, serão apresentadas algumas propostas de forma incipiente.

Uma das possibilidades de abordagem do projeto seria através do tratamento da memória, entendida como um elemento fundamental da identidade de um lugar. Segundo Mauricio Abreu16, uma vez que Santos (1994) considera que "o lugar é a extensão do acontecer solidário, entendendo-se por solidariedade a obrigação de se viver junto", o lugar seria, então, "o lócus do coletivo, do intersubjetivo". Assim, para o autor, 
“a memória de um lugar, a memória de uma cidade, é, portanto, uma memória coletiva" ${ }^{16}$.

De acordo com Maurice Halbwachs apud Abreu, "a memória coletiva é um conjunto de lembranças construídas socialmente e referenciadas a um grupo que transcende o indivíduo" ${ }^{14}$. Para Abreu,

\footnotetext{
"Há que se ter cuidado, entretanto, com a memória individual. Ela é, por definição, subjetiva. Isso quer dizer que fazemos da nossa memória o que bem queremos. Há também um outro fator para o qual é preciso atentar: o espaço da memória individual não é necessariamente, um espaço euclidiano. Nele, as localizações podem ser fluidas ou deformadas, as escalas podem ser multidimensionais e a referenciação, mais topológica do que geográfica." ${ }^{18}$
}

Neste sentido, devemos entender que as diferentes percepções e vivências experimentadas, ao longo do tempo, por diversos atores acerca do bairro do Rio Comprido criam uma memória coletiva do lugar e, por atravessar o tempo, essa está sempre se redefinindo. Para Maurice Halbwachs ${ }^{19}$, "não há memória coletiva que não se desenvolva num quadro espacial". Para o autor, existe uma inseparabilidade do tempo e do espaço na memória.

Assim, vale destacar que a memória de um lugar, ou mesmo de uma cidade, não é construída apenas por documentos escritos, mas também através de paisagens arquitetônicas e urbanísticas e, ainda, através de relatos e histórias orais. Estes últimos valorizam o campo da subjetividade e do indivíduo frente ao que seriam os documentos escritos tidos como oficiais, e constatam a hegemonia do pensamento de quem teve o privilégio de escrever esta história.

Desta forma, considerando os elementos apresentados acima, vemos aí um importante campo de pesquisa a ser aberto na escola quando da possibilidade de se trabalhar memória com os alunos do Ensino Básico. Ao assumirmos o eixo memória como parte da proposta deste projeto de extensão, temos uma gama de possibilidades de 
trabalho, que vão desde a memória individual, passando pela memória coletiva, até mesmo chegar a memória do lugar, memória da cidade e memória urbana.

Para tal, podemos trabalhar de forma interdisciplinar, abarcando as disciplinas de Geografia e História e seu aporte teórico-conceitual, mas também de forma transversal, abordando temas que perpassam estas disciplinas. Ainda também é possível trabalhar envolvendo as diferentes séries do Ensino Básico de forma conjunta, rompendo com a hierarquia do saber ligada à organização do conhecimento, conforme se avança nos anos do Ensino Fundamental e do Ensino Médio.

Neste sentido, algumas possibilidades se apresentam:

- Seria possível trabalhar com o confronto das memórias individuais de cada aluno acerca do bairro do Rio Comprido, visando construir uma memória coletiva com o grupo em questão;

- Poderíamos propor aos alunos que trabalhem as suas memórias individuais em uma perspectiva temporal, procurando refletir sobre as mudanças de perspectiva espacial vividas por eles ao longo do tempo, conforme foram ficando mais velhos;

- Ainda, seria possível confrontar as diferentes perspectivas espaciais relacionadas ao bairro do Rio Comprido em diferentes séries do Ensino Básico, abarcando as diferenças relacionadas a essas percepções de acordo com cada faixa etária;

- Por fim, poderíamos propor aos alunos trabalharem a ideia de memória coletiva no seio familiar, estimulando, desta forma, que o desenvolvimento de uma autonomia de pesquisa, a ser desenvolvida fora do ambiente escolar e da supervisão de um professor. Acreditamos, ainda, que esta atividade também serviria para a aproximação do aluno com seus familiares em prol de uma tarefa não convencional que envolva a família na construção do conhecimento e na formação do cidadão.

Uma outra proposta a ser explorada no projeto é a prática pedagógica do Estudo do Meio; essa prática foi utilizada desde experiências libertárias como da Escola Moderna 
por Ferrer e Guardia(1859-1909), Freinet (1896-1966) e mesmo Élisée Reclus(1830-1905). No Brasil, além das experiências anarquistas na Educação, a prática foi retomada pela Escola Nova na década de 60 , rechaçada pela ditadura militar e revigorada nos finais dos anos 80 por Paulo Freire no governo de Luiza Erundina em São Paulo.

O Estudo do Meio, então, pode se caracterizar por uma proposta pedagógica que pode implicar na transformação do currículo se pensado da seguinte forma:

- Planejamento: organização do que se quer estudar, objetivo, levantamento de dados, preparação de um caderno de campo, pensar as variáveis interdisciplinares;

- Trabalho de campo: ida, visita a um lugar escolhido pelo grupo, observação, descrição, caracterização, investigação do ambiente;

- Análise e prática: possibilidade da construção coletiva de um conteúdo trazido pelo estudo do meio visitado. Análise e avaliação sobre toda a proposta, empenho e organização dos conteúdos e do trabalho.

Assim, pode-se estruturar as possibilidades da transdisciplinaridade através de um processo horizontal do ensino- aprendizagem, fazendo com que a comunidade escolar (alunos, professores, educadores) paute o conteúdo vivido pelo aluno no currículo, admitindo também o contato direto do aluno com seu espaço de vivência e permitindo a construção de diálogos entre as diferentes áreas. Lopes e Pontuschka20afirmam que as atividades têm contribuído para o fortalecimento da autonomia da instituição escolar e dos professores, porque é uma alternativa às políticas propostas e vindas das secretarias de Educação e de materiais didáticos prontos, podendo fortalecer a dimensão pública de Educação, já que esta promove a discussão dos temas, e um envolvimento maior da comunidade escolar.

Ainda seguindo o horizonte da transdisciplinaridade, o presente projeto também buscará realizar pontes entre a Geografia e a História no intuito de compreender como se desdobram a produção do bairro do Rio Comprido e adjacências enquanto fenômeno urbano. Nesse intuito, o encaminhamento metodológico do projeto para alcançar tal objetivo será o de caminhar no sentido de iluminar quais foram, e ainda são, os agentes que interferiram direta e indiretamente, material e imaterialmente, na produção desse 
trecho com notória importância no contexto de espraiamento da malha urbana carioca. Achamos relevante esse caminho, pois acreditamos no espaço urbano enquanto meio, produto e condição da sociedade ${ }^{21}$, e não uma realidade produzida pela "mão invisível do mercado”, de um conjunto de capitais abstratos fora das relações sociais ${ }^{22}$.

Tomando como base o princípio de que o espaço urbano é "fragmentado e articulado, reflexo e condicionante social, um conjunto de símbolos e campo de lutas" ${ }^{23}$, alguns dos questionamentos iniciais, que abrirão portas para tantos outros, merecem ser sublinhados:

- quais os agentes sociais que produzem a cidade do Rio de Janeiro influenciam na organização do bairro do Rio Comprido e adjacências?

- quais foram as estratégias criadas por tais agentes e quais as ações concretas que permitiram, e ainda permitem, a (re)produção do tecido urbano do bairro?

Mister ressaltar que, a compreensão dos processos de produção do bairro do Rio Comprido e adjacências não podem estar presas unicamente a análises circunscritas somente ao local; toda dinâmica da cidade, todo seu histórico de intervenções, seja na natureza, seja no próprio tecido urbano, nos interessa na medida que for importante para fundamentar as ações locais.

Para tornar a compreensão da produção do bairro do Rio Comprido e adjacências mais sólida, esse viés do projeto de extensão deverá aprofundar debates que parecem já ultrapassados no senso comum; um desses debates que nos propomos a enfrentar e que merece maior dedicação analítica é conceituar o bairro.

O significado de bairro se encontra presente em diversas estudos locais que destinam poucos esforços para entender o que buscamos expressar quando nos remetemos a esse nível de análise. Assim, quando percebemos que a escala do bairro se aproxima ao espaço vivido $^{24}$, podemos aglutinar as diferentes perspectivas sobre o conceito de bairro em duas grandes formas de análise ${ }^{25}$ :

- perspectivas tradicionais: busca analisar o bairro enquanto sua funcionalidade de um ponto de vista positivista (localizando e caracterizando as áreas centrais, periféricas, nobres, invasões...); 
- perspectivas contemporâneas: métodos de análise que ressaltam críticas por meio da compreensão de relações existenciais com o bairro/cidade.

A transdisciplinaridade entre a Geografia e a História é, a princípio, necessária, já que a atuação dos vetores de produção do bairro do Rio Comprido e arredores enquanto uma parte da totalidade do fenômeno urbano carioca estão inseridos "na temporalidade e espacialidade de cada formação socioespacial capitalista”26. O próprio conceito de bairro oferece diferentes perspectivas dentro das Ciências Humanas que se apresentam, atualmente, como uma compreensão plural do fenômeno que propomos estudar.

\section{O Encontro da História com a Geografia: das possibilidades}

Trabalhar com Educação e ensino sempre será um desafio para professores e educadores, já que:

Em cada lugar, os sistemas sucessivos do acontecer social distinguem períodos diferentes, permitindo falar de hoje e de ontem. Este é o eixo das sucessões. Em cada lugar, o tempo das diversas ações e dos diversos atores e a maneira como utilizam o tempo social não são os mesmos. No viver comum de cada instante, os eventos não são sucessivos, mas concomitantes. Temos, aqui, o eixo das coexistências. ${ }^{27}$

E trabalhar com o ensino de História e de Geografia é permitir que esses diferentes tempos nos atravessem para a colaboração da interpretação dos lugares. Tendo em mente que ambas as disciplinas trabalham com a relação espaço-tempo, podemos, então, estudar o presente que existiu em algum momento do que hoje é passado sem perder de vista as categorias, teorias e metodologias que fundamentam tanto a História quando a Geografia.

Nesse contexto, a proposta de integração entre as disciplinas pode fundamentarse em regras teórico-metodológicas para que não enfraqueçam a qualidade do estudo a ser desenvolvido. $\mathrm{Na}$ intenção de alcançar esse "rigor" teórico metodológico, a indicação de Marcelo Werner ${ }^{28}$, sobre o fato de que podemos relacionar a empiricização do tempo com 
a idade dos lugares, da mesma forma que podemos proceder com as periodizações e recortes temporais e espaciais, se faz pertinente.

Dessa forma, pretende-se considerar o espaço vivido, concebido e percebido pelos alunos sem desconsiderar os pressupostos realizados pelas ciências. Dentro dessa perspectiva, é necessário reconsiderar a relação de poder estabelecida pela especialização nas disciplinas e horizontalizar o processo ensino- aprendizagem, como defendido por Silvio Gallo29 não atendendo apenas a uma interdisciplinaridade, mas sim à luz de uma transversalidade. Ele pondera que:

(...) a interdisciplinaridade é a consciência da necessidade de um interrelacionamento explicito direto entre todas as disciplinas. Em outras palavras, a interdisciplinaridade é a tentativa de superação de um processo histórico de abstração do conhecimento que culmina com a total desarticulação do saber dos nossos estudantes (e também nós, professores) tem o prazer de experimentar (...). ${ }^{30}$

O autor considera a crítica realizada por Edgar Morin31 na sua teoria da complexidade, em que "a interdisciplinaridade não dá conta de rearticular saberes fragmentados, que ela mais confirma as fronteiras entre os saberes do que as faz desaparecer". No entanto, defende a ideia de uma transversalidade "o que precisamos buscar são formas de diálogo na diferença, diálogo na multiplicidade, sem a intenção de reduzir os diferentes ao mesmo, ao uno" ${ }^{32}$.

Assim chegamos a ideia de transversalidades, criada pela filosofia francesa contemporânea para afirmar uma produção de saberes e uma circulação por entre eles que se faz de forma livre, não hierárquica, caótica. É produtiva promotora de encontros, conjunções, misturas, mestiçagens(...). ${ }^{32}$

Logo, pretende-se buscar uma aproximação e interligação de saberes a partir de conhecimentos históricos e geográficos com o objetivo de se compreender o espaço em questão estudado. Desta forma, torna-se imperativo refletir sobre como a relação entre o espaço e o tempo se desdobra, integrando uma única dimensão (espaço-tempo), tendo como seu principal vetor de interferência o homem, com suas criações, questões, dilemas 
e necessidades que ganham dimensão explicativa a partir das possibilidades e da interligação do encontro dos saberes geográficos e históricos.

Assim, perspectivas conceituais como o espaço vivido, bairro, freguesia, dentre outros que serão utilizados e estudados, receberão o suporte teórico-metodológico acima apresentado.

Acredita-se, então, que é a partir da articulação entre os saberes, históricos, geográficos e afins, que podemos enveredar por caminhos que objetivem alcançar e construir um ideal de conhecimento, que não seja hierárquico, compartimentalizado, tradicional, mas sim inovador, amplo, diversificado, crítico, respeitoso, comprometido e libertário; posturas que compreendemos serem ideais dentro da dimensão do ensinoaprendizagem.

\section{Referências}

1. CERTEAU, Michel de. A escrita da história. 2aed. Rio de Janeiro: Forense Universitária, 2008. p.77.

2. ABREU, Mauricio de A. Sobre a Memória das Cidades. In: A produção do Espaço Urbano: agentes e processos, escalas e desafios. Ana Fani Alessandri Carlos, Marcelo Lopes de Souza, Maria Encarnação Beltrão Sposito (organizadores). - 1.ed., 1a reimpressão. - São Paulo: Contexto, 2012. p. 23.

3. ABREU, Mauricio de A. A cidade, a montanha e a floresta. In: Escritos sobre espaço e história. Organização Fania Fridman, Rogério Haesbaert. - 1.ed. - Rio de Janeiro: Garamond, 2014. p. 299.

4. AMADOR, Elmo da Silva. Baía de Guanabara e ecossistemas periféricos: Homem e Natureza. Rio de Janeiro: Reproarte gráfica e Editora Ltda, 1997.

5. AMADOR, Elmo da Silva. Baía de Guanabara e ecossistemas periféricos: Homem e Natureza. Rio de Janeiro: Reproarte gráfica e Editora Ltda, 1997. 226p.

6. SANTOS, Noronha. As freguesias do Rio Antigo. Rio de Janeiro, Edições Cruzeiros, 1965.

7. FRIDMAN, Fania. Freguesias do Rio de Janeiro ao final do século XVIII.Anais: Seminário de História da Cidade e do Urbanismo, v. 10, n. 1, 2012. p.2. 
8. Rio Comprido: Histórico. Disponível em:http://riocomprido.blogspot.com.br/p/riocomprido-historico.html. Acesso em: 25/07/2016.

9. GERSON, Brasil. História das Ruas do Rio. 6aed. Rio de Janeiro: Bem-Te-Vi, 2015. p.382-383.

10. ABREU, Mauricio de A. Evolução Urbana do Rio de Janeiro. 4ªed. Rio de Janeiro: IPP, 2013

11. ABREU, Mauricio de A. Evolução Urbana do Rio de Janeiro. 4aed. Rio de Janeiro: IPP, 2013.p.39.

12. ABREU, Mauricio de A. Evolução Urbana do Rio de Janeiro. 4aed. Rio de Janeiro: IPP, 2013.p.44.

13. GERSON, Brasil. História das Ruas do Rio. 6aed. Rio de Janeiro: Bem-Te-Vi, 2015. p.383.

14. Rio Comprido: Evolução Urbana. Disponível em:http://riocomprido.blogspot.com.br/p/rio-comprido-evolução-urbana.html. Acesso em: 25/07/2016.

15. GONÇALVES, Rafael Soares. Favelas do Rio de Janeiro: História e Direito. Rio de Janeiro: Pallas: Ed. PUC-Rio, 2013.

16. ABREU, Mauricio de A. Sobre a Memória das Cidades. In: A produção do Espaço Urbano: agentes e processos, escalas e desafios. Ana Fani Alessandri Carlos, Marcelo Lopes de Souza, Maria Encarnação Beltrão Sposito (organizadores). - 1.ed., 1ª reimpressão. - São Paulo: Contexto, 2012. p. 24.

17. ABREU, Mauricio de A. Sobre a Memória das Cidades. In: A produção do Espaço Urbano: agentes e processos, escalas e desafios. Ana Fani Alessandri Carlos, Marcelo Lopes de Souza, Maria Encarnação Beltrão Sposito (organizadores). - 1.ed., 1a reimpressão. - São Paulo: Contexto, 2012. p. 26.

18. ABREU, Mauricio de A. Sobre a Memória das Cidades. In: A produção do Espaço Urbano: agentes e processos, escalas e desafios. Ana Fani Alessandri Carlos, Marcelo Lopes de Souza, Maria Encarnação Beltrão Sposito (organizadores). - 1.ed., 1 ${ }^{a}$ reimpressão. - São Paulo: Contexto, 2012. p. 25.

19. HALBWACHS, Maurice. A memória coletiva. São Paulo: Centauro, 2004, p.143. 
20. LOPES, Claudivan S; PONTUSCHKA, Nídia N. Estudo do meio: teoria e prática. Revista do Programa de Pós Graduação em Geografia. UEL. Londrina vol 18 n2.Paraná. 2009. Disponível em:

http://www.uel.br/revistas/uel/index.php/geografia/article/view/2360.Acesso: 20/7/2016.

21. SANTOS, Milton, A natureza do espaço. 2. ed. São Paulo: Editora Hucitec , 1996.

22. CORREAA, Roberto Lobato. Sobre agentes sociais, escala e produção do espaço: um texto para discussão. In: CARLOS, Ana Fani Alessandri; SOUZA, Marlo Lopes de; SPOSITO, Maria Encarnação Beltrão (orgs.). A produção do espaço urbano: agentes e processos, escalas e desafios. São Paulo: Contexto, 2011. pp. 41-51.

23. CORRÊA, Roberto Lobato. O espaço urbano. $4^{\circ}$ ed. São Paulo: Editora Ática, 2003, p. 9.

24. LEFEBVRE, Henri. A revolução urbana. Belo Horizonte: Editora UFMG, 1999.

25. PACHECO, João Batista. O Conceito Geográfico de Bairro: uma aplicação à questão do sítio Campinas/Basa e da Ilhinha. In: Revista de Políticas Públicas. São Luís - MA: UFMA, v. 5, n. 1/2, p. 90 - 104, jan./ dez. 2001.

26. CORREAA, Roberto Lobato. Sobre agentes sociais, escala e produção do espaço: um texto para discussão. In: CARLOS, Ana Fani Alessandri; SOUZA, Marlo Lopes de; SPOSITO, Maria Encarnação Beltrão (orgs.). A produção do espaço urbano: agentes e processos, escalas e desafios. São Paulo: Contexto, 2011. p. 43.

27. SANTOS, Milton. A Natureza do Espaço. São Paulo. Edusp. 2004. 159p.

28. SILVA, Marcelo Werner da. A Geografia e o estudo do passado: conceitos, periodizações e articulações espaço-temporais. Terra Brasilis, v. 1. http:// terrabrasilis.revues.org/246. Acessado em 10/9/2013. 2012.

29. GALLO, Silvio. A Organização do Currículo Currículo: entre disciplinaridades, interdisciplinaridades...e outras ideias. Programa Salto para o Futuro. Ministério da Educação, Secretaria da Educação a Distância, Ano XIX, N. 1, abr. 2009.

30. GALLO, Silvio. A Organização do Currículo Currículo: entre disciplinaridades, interdisciplinaridades...e outras ideias.Programa Salto para o Futuro. Ministério da Educação, Secretaria da Educação a Distância, Ano XIX, N. 1, abr. 2009. p.17.

31. MORIN, Edgard apud GALLO, Silvio.A Organização do Currículo Currículo: entre disciplinaridades, interdisciplinaridades...e outras ideias.Programa Salto para o Futuro. Ministério da Educação, Secretaria da Educação a Distância, Ano XIX, N. 1, abr. 2009. p.22. 
32. GALLO, Silvio. A Organização do Currículo Currículo: entre disciplinaridades, interdisciplinaridades...e outras ideias. Programa Salto para o Futuro. Ministério da Educação, Secretaria da Educação a Distância, Ano XIX, N. 1,. abr. 2009. p.23. 